\title{
Toward a critical theory of playful research in the internet age: Exploring playful research in Second Life, Minecraft, and hackerspaces/makerspaces
}

\author{
Jeremy Hunsinger* \\ *Wilfrid Laurier University, Waterloo, Ontario, Canada
}

A RTICLE INFO

Article history:

Keywords:

Research

Critical Theory

Playful Research

Transgression

Liberation

\begin{abstract}
A BSTRACT
This paper engages in the development of a critical theory of playful research. Using examples from Second Life, Minecraft, and hackerspaces/makerspaces, it argues that playful research is an intrinsic part of research ecologies. It presents the idea that research can be joyful, liberating, and transgressive in its pursuit of knowledge, and admits that the pursuit of knowledge also requires communal forgetting. With those insights, it argues that playful research is happening and that we should encourage research to be playful.
\end{abstract}

\section{Introduction}

Play occurs in a wide variety of knowledge spaces, and in producing a wide variety of knowledges. Using examples from research in Second Life, Minecraft, and on hackerspaces, this paper engages the relation between knowledge creation and play. It attempts to identify a place in critical theory for the concept of play in research, thus developing new possibilities for playful research.

Play can take the form of knowledge creation, and research can be play. Playful research is a productive state, in which knowledge creation is approached in a manner that seeks to transgress norms, in order to encourage the development of knowledge. Play is a category that spans work and leisure (Hearn, 1976). Play is also frequently dialectical: either reifying current paradigms; resisting or destroying those paradigms; or synthesising them into something new (Kuhn 1996; Lakatos 1980). Play inhabits a broad conceptual space that is oft-argued but frequently entails open-ended or unstructured activity, uncompelled, and noninstrumental, which is limited only by our imagination (Giddens 1964; Hearn 1976). Play is inherently a

Published under Creative Commons License 4.0 
realm of liberatory escape. It allows us to transgress rules by re-imagining the world differently. This paper is about play in research and research as play. It is also about the necessity of play in knowledge creation, from childhood through adulthood and into our later years. Inarguably, play combined with communication generates knowledge through those practices. It might not be scientific knowledge, nor may it always be research-based knowledge, but sometimes when researchers play, they create research-based knowledge from play.

This paper proceeds with a description of the theories involved in developing a critical theory of playful research. Following that, it explores three examples of playful research; one from Second Life ${ }^{\mathrm{TM}}$, one from Minecraft ${ }^{\mathrm{TM}}$, and one involving maker/hackerspaces. Each example has a different focus and attempts to establish a critical theory of playful research within the research as practiced in the example. The examples demonstrate and provide context for the critical theory, adding depth to the understanding of knowledge and play in research communities.

\section{Critical and ecological theories of playful research}

It should be clear that I am not primarily using theories of play from psychology or early childhood education. The theory I am using derives from both the ecological and critical perspectives on play. The ecological perspective is found somewhat in Gregory Bateson and Felix Guattari, but also more recently by Miguel Sicart (Bateson, 1987; Guattari, 2000; Sicart, 2014). This theory of play centers on the idea of the playful, which is a social state we communicate to each other that encourages us to play. The ecological perspective may not necessarily be liberating, but the critical theory of play states that play can be liberating (Hearn, 1976; Marcuse, 1971). When we combine these two perspectives, we get a sense of play that is part of the broader human life, part of an ecological system with extensive relations into all aspects of our lives. Our social, mental, and environmental ecologies all interrelate and co-construct each other and ourselves, our subjectivities, and our materialities (Guattari, 2000). Play cannot be simply extricated and analysed outside of those ecological relations. Still, society and particularly our political economy and its culture, have sought to isolate, to diminish, and to remove play from much of our life-world, in favour of productive activities. Ecological models of play resist the tendency to limit play to certain contexts and recognise the possibility that almost all actions may be playful or related to play. By making play a central relation of most action, ecological models of play allow us to define and clarify its relationality and its extension in our lives.

Contrarily, capitalism has sought to limit play because play can liberate (Hearn, 1976). Play though, is highly productive, but inarguably its non-instrumental nature limits instrumental productivity (Horkheimer, 2012). And in the control society that arose from early capitalism, to today in late capitalism, there has been a concerted attempt to dismiss play in many arenas, transforming it into leisure or otherwise (Beniger, 1989; Deleuze, 1990a, 1990b; Hearn, 1976). As such, the ecological model of play contravenes the encapsulation of play by capitalism, allowing this paper to further develop the critical models of play. 
This essay is not about playbour or gamification. Academic research can and should be playful as productive, not to the exclusion of work, nor in the neoliberal construction of work as play, which is deeply problematic (Lund, 2015; Sandoval et al., 2014). Neoliberal instrumental reason and the justification of the market undermine the nature of play and transform it into a purely productive model, leaving out any sense of emancipation or freedom (Harvey, 2011; Hearn, 1976; Mirowski \& Plehwe, 2015). The problematics of play collapsing into the playbour has been discussed elsewhere at length (Fuchs, 2016; Hesmondhalgh \& Baker, 2013; Lund, 2015). Still, here it should be noted that fundamentally it is exploitative and morally reprehensible to transform leisure activities into work activities. However, play may be part of work and may be part of labour, so there may be elements of work that can be played, and that may be an emancipatory possibility (Hearn, 1976; Marcuse, 1971). Similarly to the critiques of playbour, the critiques of gamification abound in scholarly literature, as do proposals for its applications. Indeed, there has been gamification of research, and that has had its outcomes and effects (Bogost, 2013; Conway, 2014 ; C. O'Donnell, 2014). Both playbour and gamification are very different from play in one aspect of human life: neither are emancipatory, both are instrumental to capital. Both also center on extrinsic motivations, whereas play, as noted earlier, is mostly either intrinsic or socially motivated.

It should also be said that this is not an essay about statist, administrative, or bureaucratic research, which can be the base, plodding type of work that exists without fun - though due to the functions of ideology, some may find it fun or enjoyable (Althusser, 2006; Deleuze \& Guattari, 1988; Horkheimer, 1982; Hunsinger, 2009; Lazarsfeld, 1941). The examples in this essay are about critical research, specifically critical technical practice and critical interpretive research (Agre, 1997; Boehner, David, Kaye \& Sengers, 2005; Dourish, Finlay, Sengers, \& Wright, 2004; Hunsinger, 2006). In other words, it is an essay about the joy of learning through engaging with technical systems: building them, designing them, using them, hacking them, playing them, and sometimes destroying them. These activities are part and parcel of contemporary play. They deal in the processes of knowledge creation and destruction, in that these activities allow the communicative co-construction of paradigms of knowledge (Kuhn, 1996). As the paradigms become reified through continued play, the impermanence of the opposing paradigms becomes obvious to those inside the knowledge ecology of the paradigm, and people forget or lose knowledge of that which is no longer played (Bowker, 1997, 2005; Engeström, Brown, Engeström, \& Koistinen, 1990).

Research and knowledge creation deal with teleological goals of learning more and forgetting, but also emancipation. Beyond being critical, this research is grounded in a constructivist and ecological model of knowledge, soft ontologies, and the relative flux of semiotic systems (Guattari, 1995). It recognises play, imagination, and sharing as central to research and knowledge construction and reality construction. It accepts the idea that humans create social and cultural facts, and those facts guide and structure our day-today lives and become real. Perhaps too real and thus ready to critique through play (Hearn, 1976). Importantly, this essay also engages with the impermanence of knowledge in the digital world and how the objects of knowledge are increasingly impermanent. Even with the increasing impermanence of the digital 
world, we can know things about it and about the way it was.

Play is a way of establishing and transgressing community norms. Play is a social process like knowledge: as to whether or not someone else is present, the player reflexively reconstructs relations from their culture. The imaginative function of play is part of that culture. It may rely on a human's talent, but that talent is recognised and constructed in its cultural and ecological context. Play and knowledge, while culturally diverse, are also culturally universal (Stevens Jr., 2020). Everyone has played, and everyone has known within the frameworks of the existence of those terms. Playfulness disappears from many people's lives over the years. It is enclosed by capitalism and the pursuit of livelihood as required by capitalism. People become serious about things they used to treat playfully. The enclosure of play by capitalism and its transformation into other cultural forms, such as games and sports, is also notable, as that movement is part of what transformed knowledge production into work and, for some, drudgery, instead of gleeful play.

\section{Second Life and music communities}

An illustrative example was found in the virtual world of Second Life. For a period from 2007-11, Second Life was very popular for education and research, and while research and teaching still goes on there, its popularity waned (Hunsinger \& Krotoski, 2013). The Mountaintop was the strange irrealist interplay of musical genre and community building in virtual worlds, related to French and North African rap music. It was not an experiment as much as a playful construction that became more than its affordances provided. The Mountaintop was created on an island called Kula, which was built to hold several non-profit organisations. Kula was comprised of four sims. Each sim was a virtual space that existed on one processor. The virtual space could hold a limited number of objects and a limited number of avatars. In having four sims, Kula could host more things, and the Mountaintop was one of those things. Kula housed many other projects while it existed, including Creative Commons, Brian Eno's 66 Million Paintings, Magnatune, Bookmooch, the EFF, and many other projects. The sims, which are square, were oriented as a larger square. In the middle of the square where the sims joined was a space where well over 100 avatars could experience events in an amphitheatre designed by Aimee Weber Studios. Various events occurred in this space, from watching space launches, to Judge Richard Posner giving a talk, to various book talks, etc. This theatre was notably placed amongst a circle of mountains. On the top of one of those mountains was the Mountaintop, which was a different and much simpler design. The Mountaintop was about the equivalent of 40 square meters of space that overlooked the amphitheatre. Originally intended only to watch and help manage events in the theatre, other users eventually discovered the space. It was not hidden, but nor was it advertised. Notably, when there were no events present, the Mountaintop played music (any space in Second Life can stream music or video). The Mountaintop streamed a North African French rap music station. The theme was chosen as an intervention to the nearly hegemonic North American music found in Second Life. The genre of music played on the Mountaintop stood out in comparison to the music played on 
much of the rest of Kula, which was either topically oriented, live virtual performance such as at the Dancing Tree or the amphitheatre, or Creative Commons oriented music. While the other locations on Kula had their activities, the only things that one could do at the Mountaintop were listen to this music and use the dance balls - animated scripts that allow one avatar to dance with another avatar. Word of mouth must have travelled relatively quickly because usage of the Mountaintop increased, even as usage of the whole of Kula waned, when the popularity of Second Life waned. For several months in 2006-8, there were several people using it daily, and it was by far not the only option on the island. However, even with its small size, it was occupied most of the time by people listening to music, dancing, and chatting.

\section{Figure 1}

The Mountaintop with two avatars, two sets of dance balls facing away from the amphitheatre

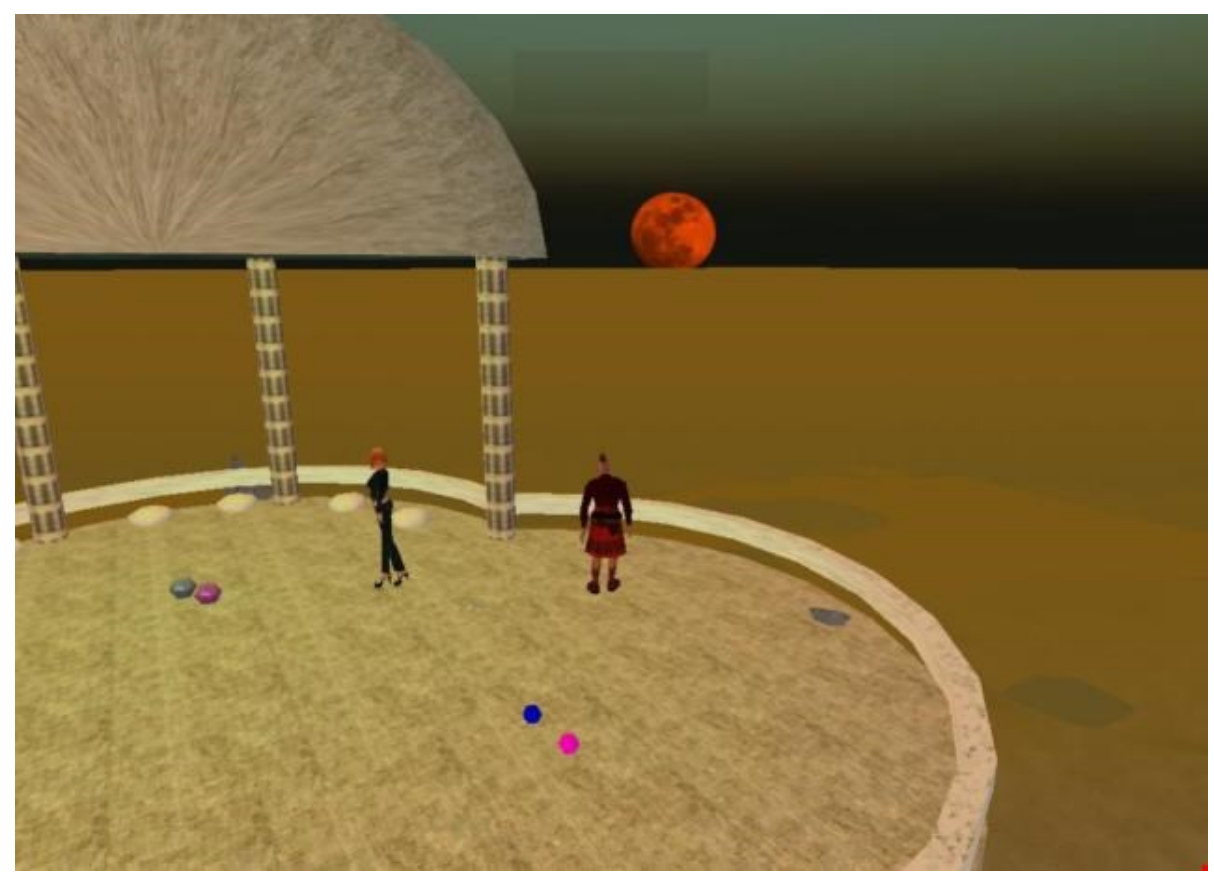

On one level, all of Kula was an experiment, much like the Edgelab that came later from Ryerson University (though Edgelab had a few more experiments). They were experiments in culture, in community-building, occasionally also in art and play. They are not experimental research, but they were undoubtedly playful research. The Mountaintop was a simple creation intended to serve a practical purpose, which over time became something more because of the music that it played. Eventually, there was even a Mountaintop user group of 40 members that used the very small space in their unique ways. It was not an intentional engagement for what it was supposed to be, but a playful intervention that gained a life of its own. It was a place for community-building and for learning, as much as anything else. The interplay of possibilities is what makes it rich as a research ecology because every new construction can be a new place to learn. What we learned about engagement and design on the Mountaintop is a lesson in the fun creation of knowledge because many people learned many things, beyond the researchers and designers.

So, by playing with things and juxtaposing opportunities, we learned quite a bit from the Mountaintop. We 
learned that there was an underserved population that appreciates North African French rap music. We learned that designed affordances are not necessarily communal affordances, and communal affordances don't necessarily map to the designed affordances. The affordances must meet the interpretive community in some manner, and there is a space of interoperation in which the community and the affordances exist in tension to create something new for themselves. This creative relationship enables people to learn about space and its co-construction.

One way we can say we learned and came to know some exciting things in Second Life is to compare aspects. The Mountaintop was not the only thing on Kula, nor was it the only music-oriented venue. There were a few others that had less or different success. Magnatune is still an ongoing business, so I won't discuss that here. There was also the Temple of Dance, which was not nearly as popular, and the Dancing Tree, which was more popular but much more extensive and addressed different needs. The Temple of Dance was designed as an Ancient Greek temple and had dancing balls. It played contemporary dance music. The Dancing Tree was a large venue that had live music and regularly streamed music. It generally played beach music when there was no live music. The Dancing Tree was advertised and had a large user group that attended it. The Temple of Dance was not advertised and had virtually no users. While this does not give us much insight or direct inference into the relative success of Mountaintop, we can, in comparison, consider that popular music is only popular for those that make it popular, and that in virtual worlds, music and community are deeply intertwingled (Dechow \& Struppa, 2015). The Mountaintop is no longer there (it ended when Kula ended) but the lessons learned about community, music, and space lived on both for the participants and the creators.

The Dancing Tree survived Kula and migrated to the Edgelab sims, but the Mountaintop did not. It was ended, and slowly after that, the community around it drifted away. The Mountaintop only now exists in a few virtual pictures, and likely won't exist as a referent for many people beyond this paper. It is essential to recognise the cultural forgetting embodied in all knowledge creation (Bowker, 1997; Olick \& Robbins, 1998). Knowledge is a system of relations that relies on the continued reconstruction of a community sustaining those relations. As the material or digital aspects of the knowledge disappear, the knowledge slowly fades. Playful knowledge or not, without the community, it rarely exists without documentation such as this paper, and inarguably this paper could be lost in the information deluge in which we live. Play as an element of creating, sustaining, and transgressing knowledge communities is increasingly important.

\section{Minecraft, crafting minds}

One other example to discuss is Minecraft. Minecraft is a game-like virtual world that can be either much more game-oriented or much more creative-oriented, as it has different modes. Minecraft multiplayer is particularly interesting in regards to creative and critical research, as many people (upwards of 100) can be online at one time, doing any number of things in the world. Like Second Life noted above, the world is 
hosted on a server, and there are limits in the affordances of the world, but even within those, the possibilities of creative play are pretty much endless. There are simulated building materials, simulated natures, and within them, simulated animals. These simulations have limited and pre-defined interactions. These interactions are their affordances, but they exist within an ecological system in the world where one can either play with the defined interactions, which is limiting, or construct possibilities to re-imagine the affordances differently. One can for instance, run around and shear virtual sheep to create wool, or one can build a giant sheep shearing robot in which the sheep live to do the job for you. The possibilities of the latter are up to the creator's imagination.

In one world, the professional and public server of GamingEdus, researchers and children shared a world, built things, and developed countless projects (L. O'Donnell, 2016). Frequently, the children were the more productive. Official research did occur and was approved as appropriate. If you were to visit the world now, even though it is dated, you would find a world with plenty of space for exploration and several thousand independent constructs spread over a massive area. Most of what went on there was knowledge creation of some sort and engagement of another. There were many relationships and identities present amongst adults and children. Academic researchers might also be builders and own a virtual 'home' that was present in the world. Children could be researching a topic for school. There were people creating art, people creating experiences, and people experiencing both.

In GamingEdus, you could 'die,' and you would respawn or be 'born again', in your bed or at 'spawn' (the first point in which you enter the world). Dying for the first time could be traumatic for new users who did not realise what would happen, so one builder made a 'death leap'. In this a new user could climb many stairs and then leap to their death, thus learning through experience that dying in the world was not terrible. However, users quickly realised that if they put their bed on top of the tower, they could spend a few minutes dying and respawning for fun, and several users did so.

While people created many things in GamingEdus, much of what was made tended to be cultural reproduction. Users tended to build houses or bases, and some built aspirational objects like mansions or hotels. Some would build mines; others would build rollercoasters. Mostly though, people made things they knew. This reproductive tendency also holds for Second Life and later for hackerspaces/makerspaces. It takes a good deal of thinking to disrupt experiences. People do tend to get normalised to the world and thus used to the experiences that they would find there.

One of the canonical experiences of the survival world is mining. You need to mine for various resources in the world to survive. One intervention in the experience of mining that surprised many of the users was an experience called Pinkcaves. Minecraft autogenerates 'caves'; caves are filled with monsters such as zombies, skeletons, and the canonical creeper. These caves might have water or lava in them, but most importantly, because they are open spaces, they expose resources for mining. Caves serve many purposes in the world, but Pinkcaves replaced the inside of the cave, the walls, with pink wool. Wool is harvested from sheep, and 
pink dye can be made from flowers. So, a user replaced all of the walls of this cave with pink wool. That does not happen in the world - someone had to spend time doing that. Then, they filled the space with sheep and dogs, which creates an odd cacophony when approached while mining underground. Pinkcaves still exist in the world. While not a massive installation, their difference is somewhat shocking and has made people think differently about what they could do in the world.

\section{Figure 2}

Pinkcaves

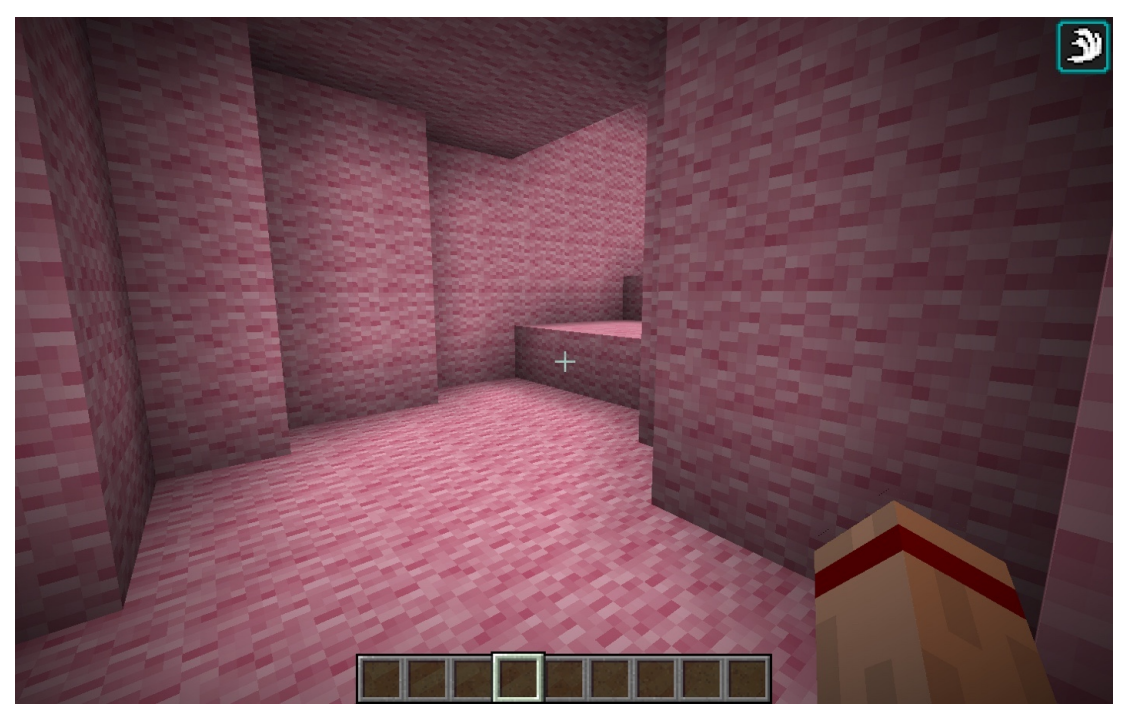

Pinkcaves was a critical intervention in Minecraft on this server. It was entertaining, surprising, and different. Pinkcaves did not occur at the beginning of the world, but after several months of creativity in the world. As an intervention, it probably did not reach all audiences, but it did reach some and changed their capacity to think about the world as something changed, that typically would not be changed. The world continues on today (though it did go offline when it moved from the Edgelab at Ryerson to a non-profit). The knowledge gained in Minecraft centres on learning about the world and learning what is possible, then operating within those parameters to have fun. Pinkcaves tweaked those parameters, and people learned things. It was not the only large construction in the world - there were many of those - but it was a unique construction that begot other similar interventions. This included using server commands to change one block type for another, in that case, orange wool. That, too, is a shocking find when one is mining and certainly changed some people's experience, but is quite different in practice to the prior intervention. However, both were playful and fun interventions into the expectations of Minecraft. Both had elements of research and intervention in the world that transformed use, and both brought about new ideas into the world. They were practical interventions in knowledge creation that used the affordances of the work to engage users and give them new possibilities for action in the world. They were liberating.

Games and virtual worlds are spaces for liberation, though most people are not liberated there, as their cultures with their hegemonic beliefs bind them. People also tend not to see the connections between their actions in those worlds. In other words, they don't unite the subjectivities of their life, but instead, they 
separate them from identifying differently in different roles. They don't realise we live ecologically in a universe constituted by our subjectivities interacting with realities. This disunity of subjectivity is not problematic, people do it all the time: the subjectivity of playing hockey is hopefully a different subjectivity than driving a truck down the interstate. The splitting of subjectivities in context though, is but another part of the encapsulation of play by capital. People divide off their playful selves into subjectivities that perform the play that they enjoy, instead of performing play their whole life. The research above, on the other hand, united play and research in critical technical practice. It intervened in the use of technology, and in the intervention allowed people to do things that they may not have otherwise done.

While the servers for GamingEdus still exist and are becoming more accessible, they were for time offline and inaccessible. This situation is critical to note, because like the virtual world examples mentioned above, knowledge relies on the existence of things to know. With the servers offline, the community that had the knowledge became fragmented, the play that sustained the community transformed as children grew up, professionals moved on to other projects, and academics progressed in their careers. The thousands of hours of construction and play in this Minecraft world could have been lost, and with it, some of the import of the play - though certain intellectual habits would have perhaps changed, and the practice might have persisted for a while. But it is crucial to consider the impermanence of knowledge, playful or not, and the act of forgetting that helps to build knowledge. Knowledge is ecological, and forgetting is part of the deterioration of the relations of the system. Playfulness and continued engagement will sustain some relations, but over time relations change and are in flux in relation to other relations, gaining or losing salience or event ontological status.

So, while knowledge was created in Minecraft in relation to the Pinkcaves, it is hard to say that any of the users of the world remember it, though it is easy to say that they were likely changed by it at the time. Whether the change persists is another question entirely. However, papers such as this provide a basis for continued engagement with the knowledge created, and encourage play that may continue the intervention's effective knowledge creation over time.

\section{Global Cupcake Challenge}

Another example is the playful international exchange of cupcakes that occurred for many years in makerspace communities, which created new shared norms around engineering creativity in context. The Global Hackerspace Cupcake Challenge happened in 2011 and 2012 (Hackerspaces, n.d.; Hunsinger, 2011). The central idea of the experiment was to develop more interconnections between hackerspaces. The challenge was to deliver at least one cupcake to another hackerspace via the mail, without that cupcake being damaged in any manner. The event was construed as a competition, with marks being given for creativity in the delivery method, the quality of the ingredients, the appearance, the taste, and finally, the condition of the cupcake (Hackerspaces, n.d.). Several unboxing videos exist on YouTube - on those, you can see the results. 
The results unsurprisingly were generally successful, with cupcakes arriving relatively fine, with a few worse for wear.

The cupcakes were only part of the ecology of knowledge developed in the cupcake exchange. For many groups, the cupcake challenge was about community and collaboration. People worked together to perform various parts of the process. They learned from each other, had meetings, completed tasks. Intuitively making and sending cupcakes should be a simple task, but as you add people, the project becomes increasingly complex. As noted above, it was already tricky because of the rules and the international nature of the competition. You add collaboration, and then one other level of complexity, with the creation and streaming of videos.

These videos are mostly lost now (Hunsinger, 2017). A few are left online, but over time the political economy of internet streaming in 2011-12, and the use of platforms such as Ustream, has led to their disappearance from the internet. Their disappearance is a complication for researchers studying them, and perhaps a difficulty for the hackerspaces, which lost their content when Ustream changed their archival policies. This loss of content is, in part, a loss of shared cultural artefacts and, likely for some, the referent memories of those happenings. The relations of memories, referents, social, mental, and environmental conditions all impact the knowing and the known. In this case, the hackerspaces and makerspaces performed this act almost a decade ago, and now much of the evidence of that act is missing. So, while the individuals know what occurred to some extent, some perhaps no longer know precisely what happened. Playfulness in knowledge creation doesn't ensure the continuation of knowledge or the community that sustains it.

The playfulness and fun do help bond the community together. The fun had in this project is evident in the public videos, both in the boxing and the unboxing of the cupcakes and, to some extent, in the eating. The research and dissemination of research that happens are also obvious. As in boxing up the cupcakes: people put good engineering knowledge and technical practices into their designs. Some do lean more artistic, but generally, even the artistic models of sending a cupcake tend to use technical principles centred around questions of physics, mechanics, and dynamics. Like the classic children's physics competition of dropping a fresh egg from a building, there are some basic understandings of the context of the time, space, physics, etc. The primary difference with this project is international shipping, which occasionally yielded additional damage and additional time.

The playfulness of this sort of activity is also quite clear. While hackerspaces and makerspaces are not generally thought of as playful enterprises, they are communal enterprises, and as such, they usually engage in activities that are playful and fun. Science and research are also communal enterprises (Merton, 1942). They too can be playful, and they should be. In part because playing opens up possibilities of resistance to hegemonic ideals, and that alone might break through some epistemic barriers that have been communally established. Epistemic communities frequently establish boundaries and perform boundary-work (Gieryn, 
1983; Knorr-Cetina, 1999; Star \& Griesemer, 1989). Playfulness can help break those boundaries and set new boundaries, aiding knowledge creation.

The knowledge created in this practice centred on the shipping design, especially in light of the challenge's goal of creativity. Of the videos that are left that exemplify the project, one can see the admiration that some of the receivers have for the novelty of the creation. One can see the joy in understanding how the shipping method was put together, even in the less than successful versions. There is a clear relationship between their understanding of the cupcake container and the cupcake container that they sent, and some video participants posit what they could have done better.

In short, cupcake shipping systems were posited, researched, designed, and implemented. They were received, disassembled, and people learned about them. It seems like a simple interaction, but yet people came away knowing more things than they did before. Some learned more about what to do, and some learned more about what not to do, but almost everyone assuredly learned something. This is playful research and playful research dissemination.

Hackerspaces embody, to some extent, the spirit of fun learning and fun research because they are already spaces where you are encouraged to pursue your own goals freely. They are andragogical spaces; selfdirected, but communal. In regards to the cupcake challenge, they were acting communally; also, they were working to encourage more interconnection between these spaces. In having these goals, the activity they engaged in was, in part, transformed to be a bit more serious, but still was playful. While there is somewhat of a community amongst spaces now, I do not think it as well-established as the originators of the cupcake challenge would have imagined.

Makerspaces and hackerspaces are collaborative research spaces where people can build projects, develop ideas, and pursue projects. Unsurprisingly, they are less centres of innovation, than they are centres of replication and reproduction (Hunsinger, 2016). Most of the innovation related to hackerspaces and makerspaces occurs in the communication of needs, and thus markets between the users of the makerspaces and the companies that service them. They are less as places of 'inventing to learn' than of 'reproducing to learn'. This is unsurprising, as most of our learning institutions are reproductive (Bourdieu \& Passeron, 1990). This is not to say that they don't occasionally innovate, but that the innovation they have is rare, like all innovation.

Innovation is also difficult, and without a sense of play and the freedom of that sense, it is nearly impossible. It is the same with science and research. Both are incremental enterprises, where people are embedded in traditions with well-defined research trajectories that exist within a broad knowledge ecology with thousands of relations. Depending on the academic world, lab, discipline, and other engagements, they might not be able even to see the broader picture where their work can be playful or fun. They can use play though to transgress some of their boundaries and possibly move beyond incremental research. They can engage in their andragogical learning and find alternatives through this play, without being necessarily 
directed or bound.

Hackerspaces and makerspaces, in providing a space outside the lab where all kinds of lab-like activities may safely occur, can allow for this sort of learning. Similarly, engaging in virtual worlds and games where the reality is not the same can provide means of finding new limits too. Changing situation allows people to change their attitude to become more playful or less playful. Some places seem inherently less playful than others within specific cultural contexts, and thus play is suppressed, and in other environments, play is openly encouraged. In the examples that I provided above, play occurs, but in each of those other activities arise also. GamingEdus has a separate server for Ontario Schools. Second Life has a myriad of businesses and other activities going on at all times. Hackerspaces and makerspaces are full of people going in their own and communal directions.

\section{Conclusion}

There are innumerable anecdotal examples of people finding inspiration to solve scientific and other research problems while playing games. So, it should not be surprising that having fun and being playful in research is already encouraged in many research enterprises. This paper does not engage with that deep history, but recognises its existence.

Instead, this paper attempts to show that play and playfulness do create knowledge in other areas, specifically in critical research. It also argues that even knowledge is impermanent and requires a community and ecology to sustain it. In reflecting on the examples in this paper, we can learn many things about a possible critical theory of playful research. We can learn that it is frequently dialectical: playfully building paradigms, playfully destroying them too, and occasionally synthesising new paradigms. We can learn that playful research is frequently transgressive to the mutually constituted normal operation of research, and with that, it helps to co-construct alternative relations within knowledge communities. In this co-construction, playful research also allows for the creation of new paradigms.

Without getting too far down the research/scientific paradigms rabbit hole of Kuhn, Lakatos, and progeny, it is easy to see that playful research involves much more than the production of knowledge. It also involves the forgetting of knowledge, which happens in the communities that sustain the knowledge. Each of the examples provided evidence the transgression of communities, development of knowledge, and forgetting of knowledge, which allows for the further development of knowledge. The ecologies of knowledge in which we exist require this forgetting, much like they require remembering, as it is the inter-relation of knowledge within their ecologies which allows for knowledge creation. Fundamentally, there must be communicating knowledge communities both remembering and forgetting to have a living research community, and within those, there will almost always be some playful research.

Playful research is happening; it happens all the time. Some may not call it research, but that is up to its 
traditions, communities, academic disciplines, and such to define. Knowledge is being created and played with, online and off. There are many reasons to encourage research to be playful, but the primary one is the creation and sustenance of knowledge communities - that is, the people that know the same things and likely can play the same things. 


\section{References}

Agre, P. E. (1997). Computing as a social practice. In P. E. Agre \& D. Schuler (Eds.), Reinventing technology, rediscovering community. (pp. 1-17). Greenwich, CT: Ablex.

Althusser, L. (2006). Ideology and ideological state apparatuses (notes towards an investigation). In A. Sharma \& A. Gupta (Eds.), The anthropology of the state: A reader. (pp. 86-111). Malden, MA: Blackwell. Bateson, G. (1987). Steps to an ecology of mind: Collected essays in anthropology, psychiatry, evolution, and epistemology. Northvale, NJ: Jason Aronson.

Beniger, J. R. (1989). The control revolution: Technological and economic origins of the information society. Cambridge, MA: Harvard University Press.

Boehner, K., David, S., Kaye, J., \& Sengers, P. (2005, April). Critical technical practice as a methodology for values in design. The CHI 2005 Workshop on Quality, Values, and Choices, Portland, OR.

Bogost, I. (2013). Exploitationware. In R. Colby, M. S. S. Johnson, \& R. Shultz Colby (Eds.),

Rhetoric/composition/play through video games. (pp. 139-147). New York, NY: Palgrave Macmillan.

Bourdieu, P., \& Passeron, J. C. (1990). Reproduction in education, society, and culture (1990 ed.). London: SAGE in association with Theory, Culture \& Society, Department of Administrative and Social Studies, Teesside Polytechnic.

Bowker, G. C. (1997). Lest we remember: Organizational forgetting and the production of knowledge. Accounting Management and Information Technologies, 7(3), 113-138. doi:10.1016/S0959-8022(97)90001-1

Bowker, G. C. (2005). Memory practices in the sciences. Cambridge, MA: The MIT Press.

Conway, S. (2014). Zombification?: Gamification, motivation, and the user. Journal of Gaming \& Virtual Worlds, 6(2), 129-141. doi:10.1386/jgvw.6.2.129_1

Dechow, D. R., \& Struppa, D. C. (Eds.). (2015). Intertwingled: The work and influence of Ted Nelson. Springer Open. doi:10.1007/978-3-319-16925-5

Deleuze, G. (1990a). Control and becoming. In Negotiations: 1972-1990 (M. Joughin, Trans.). (pp.169-176). New York, NY: Columbia University Press.

Deleuze, G. (1990b). Postscript on control societies. In Negotiations: 1972-1990 (M. Joughin, Trans.). (pp.177182). New York, NY: Columbia University Press.

Deleuze, G., \& Guattari, F. (1988). A thousand plateaus: Capitalism and schizophrenia (B. Massumi, Trans.). London: Athlone Press.

Dourish, P., Finlay, J., Sengers, P., \& Wright, P. (2004). Reflective HCI: Towards a critical technical practice. CHI'04 Extended Abstracts on Human Factors in Computing Systems, Vienna, Austria, 1727-1728. 
doi:10.1145/985921.986203

Engeström, Y., Brown, K., Engeström, R., \& Koistinen, K. (1990). Organizational forgetting: An activitytheoretical perspective.

Engeström, Y., Brown, K., Engeström, R., \& Koistinen, K. (1990). Organizational forgetting: An activitytheoretical perspective. In D. Middleton \& D. Edwards (Eds.), Collective remembering. (pp. 139-168). London: SAGE.

Fuchs, C. (2016). Herbert Marcuse and social media. Radical Philosophy Review, 19(1), 111-141. doi:10.5840/radphilrev20163950

Gieryn, T. F. (1983). Boundary-work and the demarcation of science from non-science: Strains and interests in professional ideologies of scientists. American Sociological Review, 48(6), 781-795. doi:10.2307/2095325

Guattari, F. (1995). Chaosmosis: An ethicoaesthetic paradigm (P. Bains \& J. Pefanis, Trans.). Bloomington, IN: Indiana University Press.

Guattari, F. (2000). The three ecologies (I. Pindar \& P. Sutton, Trans.). London: Athlone Press.

Hackerspaces. (n.d.). http://hackerspaces.org/wiki/

Harvey, D. (2011). A brief history of neoliberalism. (Reprint). Oxford: Oxford University Press.

Hearn, F. (1976). Toward a critical theory of play. Telos, 1976(30), 145-160. doi:10.3817/1276030145

Hesmondhalgh, D., \& Baker, S. (2013). Creative labour: Media work in three cultural industries. London:

Routledge.

Horkheimer, M. (1982). Traditional and Critical Theory. In Critical theory: Selected essays (M. J. O'Connell, Trans.). (pp. 188-243). New York, NY: Continuum.

Horkheimer, M. (2012). Critique of instrumental reason (M. J. O'Connell, Trans.). Brooklyn, NY: Verso.

Hunsinger, J. (2006). The political economy of the internet: Contesting capitalism, the spirit of informationalism, and virtual learning environments. In J. Weiss, J. Nolan J., Hunsinger, \& P. Trifonas (Eds.). The international handbook of Virtual Learning Environments. (pp. 189-206). Dordrecht: Springer.

Hunsinger, J. (2009). Toward nomadological cyberinfrastructures. In J. Hunsinger, L. Klastrup, \& M. Allen (Eds.), International handbook of internet research. (pp. 167-178). Dordrecht: Springer.

Hunsinger, J. (2011). The social workshop as PLE: lessons from hacklabs. The PLE Conference, Portsmouth, UK. Hunsinger, J. (2016). Our knowledge is our market: Consuming the DIY world. In A. Day (Ed.), DIY utopia: cultural imagination and the remaking of the possible. (pp. 85-102). Lanham, MD: Lexington Books.

Hunsinger, J. (2017). Hacking together globally. Digital Culture \& Society, 3(1), 95-108. doi:10.14361/dcs-20170106 
Hunsinger, J., \& Krotoski, A. (Eds.). (2013). Learning and research in virtual worlds. Abingdon: Routledge. Knorr-Cetina, K. (1999). Epistemic cultures: How the sciences make knowledge. Cambridge, MA: Harvard University Press.

Kuhn, T. S. (1996). The structure of scientific revolutions. Chicago, IL: University of Chicago Press.

Lazarsfeld, P. F. (1941). Remarks on administrative and critical communications research. Zeitschrift Für Sozialforschung, 9(1), 2-16. doi:10.5840/zfs1941912

Lund, A. (2015). A contribution to a critique of the concept playbour. In C. Fuchs \& E. Fisher (Eds.), Reconsidering value and labour in the digital age. (pp. 63-79). London: Palgrave Macmillan.

Marcuse, H. (1971). An Essay on Liberation. Boston, MA: Beacon Press.

Merton, R. K. (1942). A note on science and democracy. Journal of Legal and Political Sociology, 1(1-2), 115-126.

Mirowski, P., \& Plehwe, D. (2015). The road from Mont Pèlerin: The making of the neoliberal thought collective, with a new preface. Cambridge, MA: Harvard University Press.

O’Donnell, C. (2014). Getting played: Gamification and the rise of algorithmic surveillance. Surveillance $\mathcal{E}$ Society, 12(3), 349-359. doi:10.24908/ss.v12i3.5017

O’Donnell, L. (2016). Building blocks: Children's open-ended play in Minecraft (Masters thesis). Retrieved from https://digital.library.ryerson.ca/islandora/object/RULA\%3A6781

Olick, J., \& Robbins, J. (1998). Social memory studies: From "collective memory" to the historical sociology of mnemonic practices. Annual Review of Sociology, 24, 105-140.

Sandoval, M., Fuchs, C., Prodnik, J. A., Sevignani, S., \& Allmer, T. (2014). Introduction: Philosophers of the world unite! Theorising digital labour and virtual work - definitions, dimensions, and forms. TripleC: Communication, Capitalism E Critique. Open Access Journal for a Global Sustainable Information Society, 12(2). doi:10.31269/triplec.v12i2.622

Sicart, M. (2014). Play matters. Cambridge, MA: The MIT Press.

Star, S. L., \& Griesemer, J. R. (1989). Institutional ecology, “translations” and boundary objects: Amateurs and professionals in Berkeley's museum of vertebrate zoology, 1907-39. Social Studies of Science, 19, 387-420. Stevens Jr., P. (2020). Yes, we need a neuroscience of play. International Journal of Play, 9(1), 160-169. doi:10.1080/21594937.2020.1720147 